\begin{abstract}
Iranica
Abstracta Iranica Revue bibliographique pour le domaine irano-aryen

Volume 34-35-36 | 2017

Comptes rendus des publications de 2011-2013
\end{abstract}

\title{
John Curtis. The Cyrus Cylinder and Ancient Persia
}

\section{Rémy Boucharlat}

\section{OpenEdition}

Journals

Édition électronique

URL : http://journals.openedition.org/abstractairanica/41787

DOI : 10.4000/abstractairanica.41787

ISSN : 1961-960X

Éditeur :

CNRS (UMR 7528 Mondes iraniens et indiens), Éditions de l'IFRI

\section{Référence électronique}

Rémy Boucharlat, "John Curtis. The Cyrus Cylinder and Ancient Persia », Abstracta Iranica [En ligne] Volume 34-35-36 | 2017, document 104, mis en ligne le 30 décembre 2016, consulté le 02 octobre 2020. URL : http://journals.openedition.org/abstractairanica/41787 ; DOI : https://doi.org/10.4000/ abstractairanica.41787

Ce document a été généré automatiquement le 2 octobre 2020.

Tous droits réservés 


\title{
John Curtis. The Cyrus Cylinder and Ancient Persia
}

\author{
Rémy Boucharlat
}

\section{RÉFÉRENCE}

John Curtis. The Cyrus Cylinder and Ancient Persia. London, The British Museum Press, 2013, 144 p., 85 ill.

1 À la suite de la présentation du Cylindre de Cyrus prêté par le British Museum au Musée National d'Iran en 2010, cet objet célèbre(supprimer « il ») a fait un grand «tour » aux USA tout au long de l'année 2013. À cette occasion l'A., qui était jusqu'alors keeper au BM et spécialiste de la période perse, a écrit cet ouvrage. Il présente l'histoire de l'empire achéménide, les villes en Iran ou en dehors de ce pays, l'architecture palatiale et des objets contemporains (monnaies, sceaux, Trésor de l'Oxus). Ces derniers sont illustrés par les collections conservées au BM. Le Cylindre lui-même n'est pas présenté ici, mais il fait l'objet d'une étude générale dans un autre ouvrage publié en même temps que celui-ci par I. Finkel. De lecture agréable et très largement illustré, ce petit livre n'a pas d'autre prétention que d'être un ouvrage de vulgarisation et de mise en valeur des collections du BM sur la période achéménide.

\section{AUTEURS}

RÉMY BOUCHARLAT

CNRS, Lyon 